\title{
AC 2009-86: CONNECTING WITH ALUMNI: AN EXPERIMENT IN SOCIAL NETWORKING USING FACEBOOK GROUPS
}

\section{John K. Estell, Ohio Northern University}

John K. Estell is Chair of the Electrical \& Computer Engineering and Computer Science Department, and Professor of Computer Engineering and Computer Science, at Ohio Northern University. He received his doctorate from the University of Illinois at Urbana-Champaign. His areas of research include simplifying the outcomes assessment process, first-year engineering instruction, and the pedagogical aspects of writing computer games. Dr. Estell is a Senior Member of IEEE, and a member of ACM, ASEE, Tau Beta Pi, Eta Kappa Nu, and Upsilon Pi Epsilon. 


\section{Connecting with Alumni: An Experiment in Social Networking using Facebook Groups}

\section{Introduction}

One of the more difficult aspects of complying with the ABET criteria concerns the collection of data in support of Criterion 2, Program Educational Objectives. The primary issue involves not only possessing valid contact information for graduates, but also maintaining a relationship with one's graduates such that there is an inherent willingness to participate in the assessment process when an alumni survey is received. Unfortunately, low response rates, sometimes even in the single digits, are often the norm, making evaluation of the assessment data difficult. The traditional methods of maintaining relationships with alumni have not been overly effective for obtaining such data, so why not try something different? This paper presents an initiative undertaken by the Electrical \& Computer Engineering and Computer Science (ECCS) Department at Ohio Northern University to use the social network service Facebook as an electronic mechanism for better developing and maintaining communications between the department and its alumni, and in so doing provide greater opportunities for increasing alumni participation rates regarding program educational objectives assessment.

\section{Background: Social Network Services and Facebook}

Social network services are a relatively new phenomenon, offering ease of access and providing a variety of modes of interaction between members. Boyd and Ellison define social network services as web-based services that allow individuals to construct a public or semi-public profile within a bounded system, articulate a list of other users with whom they share a connection, and view and traverse their list of connections and those made by others within the system ${ }^{1}$. The concept of a social network service, however, is hardly new; as examples, Free-Net and similar community-oriented networks have been available since the early 1990s, bulletin board systems were popular during the late 1970s and early 1980s, and Usenet newsgroups have been around since $1979^{2}$. Additionally, in their seminal 1968 paper, Licklider and Taylor prognosticated that telecommunication through the network would be a natural extension of face-to-face communication, with life for the on-line individual being happier "because the people with whom one interacts most strongly will be selected more by commonality of interests and goals than by accidents of proximity",

Modern-day social network services, as defined above, have been in place since the establishment of Classmates.com for connecting friends and acquaintances from one's high school in $1995^{4}$. One of the most popular social network websites is Facebook (www.facebook.com). Named after the paper "face books" distributed at many academic institutions that depict members of a campus community, Facebook has acquired over 150 million active users worldwide since its inception in $2004^{5}$. Users are required to register, with one email address associated per Facebook account; however, there is no charge to use the service. Users are encouraged to create a profile featuring both basic and personal information regarding items such as birthday, hometown, relationship status, education, work, activities, and interests; these items are formed into links on one's "Info" page. By traversing a particular link, 
one can find other Facebook members sharing that similar attribute, background or interest. Users are also asked to designate one or more networks to belong to; as Facebook was originally marketed to college students, the predominant type of network memberships are those specifying a university affiliation, although there are other networks associated with corporations and geographical regions.

The primary means of networking on Facebook is through the establishment of "friends" - those fellow users of Facebook whom are granted access to one's Facebook profile page. Generally, users with "friends" relationships are those who have a real-life relationship with that individual. By being a friend, one has access to a variety of applications allowing for sharing and interacting between users. The "Photo" application allows for the uploading of photos and for their organization into albums; both the user and friends of that user can leave comments with a particular photo, or "tag" (i.e., label) Facebook members that appear in a photo. Each album can have associated with it a different privacy setting, allowing for sharing to an entire network or just to a small circle of friends. The "Wall" application allows friends to post messages upon a user's profile page; these postings are made visible to anyone who has permission to view that profile page. The "Status" application allows a user to inform friends as to current location or activity through means of a short message; these status updates appear on both one's Facebook home page and in the "News Feed" on friends' pages; this application allows for comments by friends to be added. The "Events" application allows one to schedule an event and then invite other Facebook users to it; this includes the ability to set up RSVPs for tracking planned attendance. Finally, the "Inbox" application serves as a mail facility that is internal to Facebook. This application allows open access in that you can send a message to any Facebook member; however, users are prohibited from sending multiple messages beyond deliberately unspecified limits in order to prevent spam.

As social networking often involves those sharing common interests and activities forming online communities, Facebook facilitates this interaction via the establishment of Facebook Groups by its members, thereby providing convenient access to built-in features such as message boards, posting of photos and videos, and event announcements. This allows both the users and the administrators of Facebook Groups can focus on content, as Facebook handles all of the implementation and persistence details. Facebook Groups can be created for just about any purpose, from a local forum for complaining about the failure of an institution to cancel classes when the wind chill is $-40^{\circ} \mathrm{C}$, to a site for fans of an amusement park, to instruments for promoting political activism and social change in countries where the freedoms of speech and assembly are limited by the state ${ }^{6,7,8}$. A Facebook Group can be created by anyone; that person, or those who are then designated as officers of the group, can control what features (such as a Wall, a discussion board, photos, videos, and posted items) are enabled. Groups can be "open" (where anyone can join, or can view group information and content), "closed" (where an administrator must approve requests to join the group, and only group members has access to the features), or "secret" (where membership is by invitation only). Officers of the group have the ability to send messages to all group members, post events, or censor inappropriate material. 


\section{Creating a Facebook Group for Your Alumni: Some Guidelines}

The creation of a Facebook Group is relatively straightforward; it begins by going to the "Groups" application and clicking on the "Create a New Group" button. First, information regarding the group is requested. At a minimum, one must enter a name and description for the group; additionally, Facebook requires that the group be categorized by both category and type from a provided list of classifications. It is important that, for your alumni to be able to find your group, a title needs to be provided that clearly states the name of the program, the name of the institution, and the word "alumni". The description field should be used to reiterate the title information, provide appropriate details regarding the purpose of the group, and welcome the group's utilization by alumni. An appropriate category for an alumni group is "Organizations"; after this category is selected, choose "Academic Organizations" from the type field. One important, albeit optional, selection is the specification of the network. The group creator has the option of making the group available to all of Facebook or just a network to which the creator belongs. Here it is recommend that the group should be accessible to all. While limiting it to one's academic institutional network does have some benefits, such as the ease of which one can promote the group amongst the members of the network, it must be pointed out that the ultimate goal is to connect with one's alumni. In order to join a school's network, one must have a valid e-mail address associated with that institution; those users who join Facebook after having graduated from an institution will most likely not have the ability to join their school's network because of the lack of an acceptable e-mail address.

In the second step of the group creation process, Facebook allows for customization by the uploading of an image containing a relevant logo or photo; for our alumni group it was decided to use a photo of a student working in one of our laboratories that captured the lab-intensive nature of our program. Several options are presented as part of this step regarding the features to be enabled. Given that one wants to encourage alumni to use the group, it was decided to allow all items (showing related groups and events; and enabling the discussion board, Wall, photos, videos, and postings features) to be fully accessible to all group members. As part of this step one must also specify whether the group is "open", "closed", or "secret"; while "secret" is definitely not a viable option, arguments can be made in favor of either having the group "open" or "closed". The primary difference is that an "open" group allows anyone to see group information and content whereas the "closed" group requires administrative approval to join, only upon which one can access group content such as the Wall or the discussion board. Our approach was to make our alumni group open, which had the side benefits of allowing alumni ready access to the group upon learning of the existence of the group and allowing group members to help spread the word about the existence of the group via invitations to their former classmates. Another aspect to consider is that, when one joins a group, a message to that effect appears in the news feeds of the friends of that individual; this constitutes a form of viral advertising, complete with a ready-made link back to the group. Additionally, by making the group "open", a prospective group member has the ability to look around prior to making a commitment. It should be noted that, regardless of the degree of openness, an administrator does have the ability to remove a group member if circumstances warrant it. At this point, the alumni group is active and its page is visible to those who have been permitted access. Figure 1 shows the Facebook Group page established for the alumni of the Ohio Northern ECCS Department. 


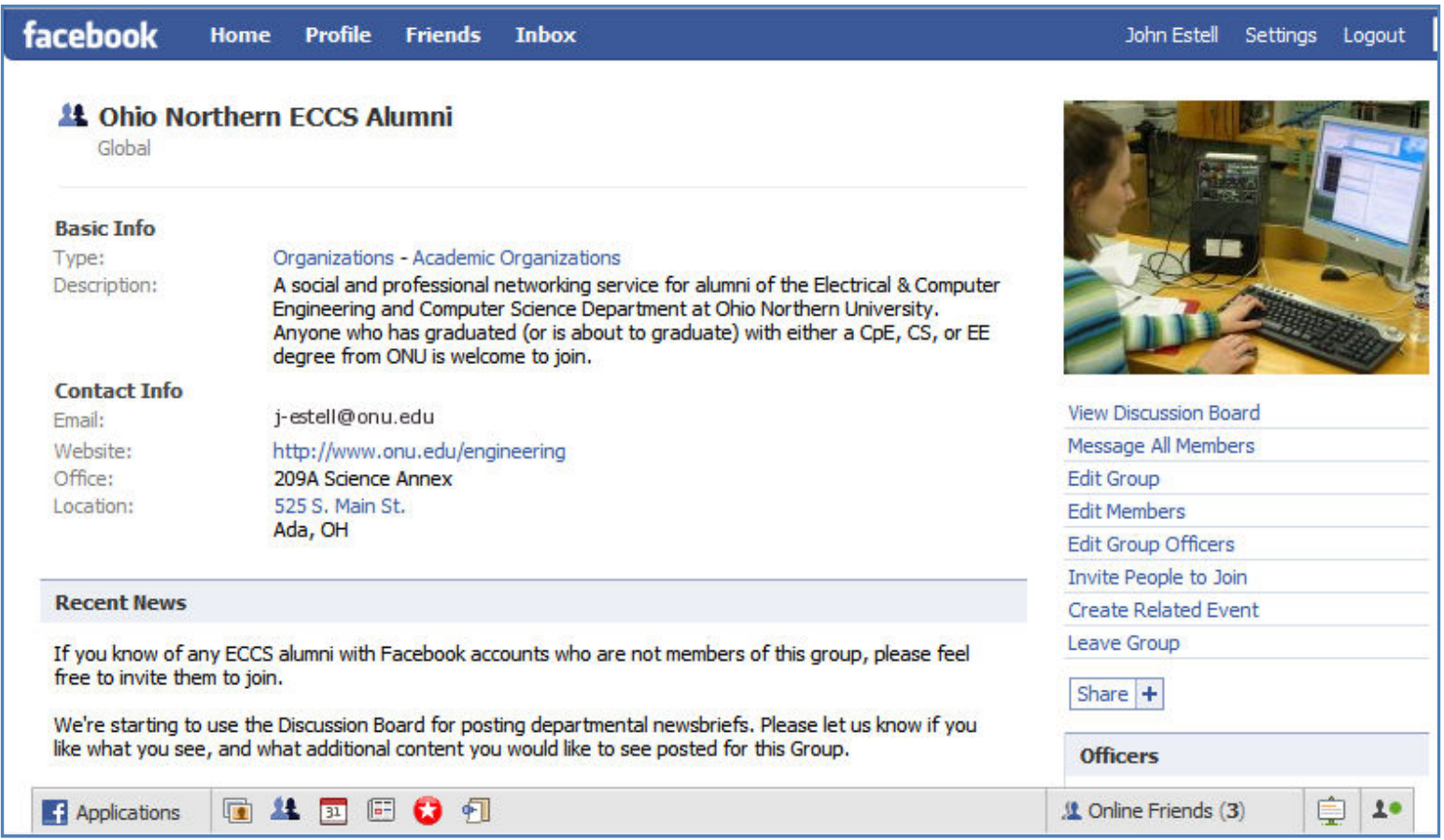

Figure 1. Ohio Northern ECCS Alumni Facebook Page.

The third step of the process involves inviting Facebook members to join the group. There are three direct methods by which this can be done. The easiest way is to invite one's Facebook friends; the interface provided by Facebook for this step includes a list of one's friends, with a checkbox next to each name for indicating whom to invite. The first members of our alumni group joined through such an invitation, as they had a "friends" relationship with the group's administrator.

The second method involves sending messages to Facebook members who are known alumni. As our department has a considerable number of alumni, we did not undertake an exhaustive mechanism for contacting all of them; instead, we limited ourselves to the last seven graduating cohorts, from 2002 to 2008, and searched Facebook to determine whether a graduate was or was not a Facebook member. Table 1 illustrates the results of this search.

Table 1. Ohio Northern ECCS Alumni on Facebook (as of 16 January 2009)

\begin{tabular}{|c|c|c|r|}
\hline Graduation & Cohort & \multicolumn{2}{|c|}{ Graduates on Facebook } \\
\cline { 3 - 4 } Size & 33 & Maximum & Minimum \\
\hline 2008 & $27(82 \%)$ & $27(82 \%)$ \\
\hline 2007 & 24 & $20(83 \%)$ & $20(83 \%)$ \\
\hline 2006 & 38 & $34(89 \%)$ & $31(82 \%)$ \\
\hline 2005 & 24 & $18(75 \%)$ & $13(54 \%)$ \\
\hline 2004 & 46 & $22(49 \%)$ & $14(30 \%)$ \\
\hline 2003 & 47 & $25(53 \%)$ & $10(21 \%)$ \\
\hline 2002 & 37 & $20(54 \%)$ & $6(16 \%)$ \\
\hline TOTAL & $\mathbf{2 4 9}$ & $\mathbf{1 6 6}(\mathbf{6 7 \%})$ & $\mathbf{1 2 1}(\mathbf{4 9 \%})$ \\
\hline
\end{tabular}


It is interesting to note that, as one goes back in time, it becomes harder to identify whether a Facebook member is a member of a graduation cohort. For the last two graduation cohorts, it was readily apparent when an alumnus was found, as they were members of the same network as the faculty member performing the search; additionally, when Facebook finds multiple members having the same name, the names of those belonging to the searcher's network are presented first. There were other cases where a person was not a member of the institution's network, but one could determine that it was an alumnus, and not just someone else with the same name, through an examination of the list of their friends, as one would then see the names of other known alumni. However, many Facebook members choose not to make their friends list public; in those cases, it cannot be determined if a person is an alumnus, especially for those alumni with common names. Table 1 illustrates this uncertainty with the maximum and minimum columns. The minimum column indicates the number of graduates for that year that are known to be on Facebook; the maximum column includes the names of those alumni who are of unknown status in that the name was found, but the account could not be verified as belonging to the actual alumnus.

When contacting alumni using Facebook, one can use the "Send a Message" link returned as part of the search process. Given that manually contacting alumni is a time-consuming process, a form letter that included the URL of the Ohio Northern ECCS Alumni Group was created so that it could be copied and pasted into the Message application; the only thing that changed for each message sent was the salutation. One unexpected consequence of this approach occurred when trying to contact a large number of alumni at one time. Facebook is very vigilant regarding the sending of spam to its members; because of the form letter approach, a warning of potential spamming activity was displayed by Facebook when attempting to send out our twelfth message. Subsequently, no more than ten messages were sent out at a time and a wait of at least an hour was taken before doing another batch; because of such precautions, no further warnings were received.

The third method for letting alumni know about your Facebook Group is through regular e-mail. Facebook does provide the ability to enter in e-mail addresses for this purpose, but you can also send e-mail via traditional applications such as Microsoft Outlook and provide the URL of the Facebook Group as part of the body of the message. This was done in a couple of cases where the department had a valid e-mail address for the alumnus but could not determine if that alumnus had a Facebook account.

There are two additional, albeit indirect, methods for alumni to learn about your Facebook Group. The first is through the initiative of alumni who are already members of the group utilizing their social networks to contact other alumni and inviting them to join. The second is through a Facebook member using the search facility on the "Groups" page to look for groups related to his or her alma mater, hence the need to use a meaningful group name that can be easily found through use of such a search. Our ECCS Alumni Facebook Group contains several members who either joined through the invitation of current group members, or were able to find the group on their own through a search. 
Table 2 presents the current total population, broken down by graduating cohort, of the Ohio Northern ECCS Alumni Facebook Group. The percentages provided in the two rightmost columns indicate the participation rate for each cohort in terms of the number of ECCS Alumni Facebook Group members related to the cohort size and in terms of the number of group members related to the possible maximum number in a cohort who are, or might be, Facebook members. This final column constitutes a minimum bound for that cohort's Facebook members participation rate.

Table 2. Ohio Northern ECCS Alumni Facebook Data (as of 16 January 2009)

\begin{tabular}{|c|c|c|c|c|}
\hline $\begin{array}{c}\text { Graduation } \\
\text { Year }\end{array}$ & $\begin{array}{c}\text { Cohort } \\
\text { Size }\end{array}$ & $\begin{array}{c}\text { Members of } \\
\text { Alumni Group }\end{array}$ & $\begin{array}{c}\text { Percent } \\
\text { of Cohort }\end{array}$ & $\begin{array}{c}\text { Percent of Cohort } \\
\text { Facebook Members }\end{array}$ \\
\hline 2008 & 33 & 17 & 52 & 63 \\
\hline 2007 & 24 & 13 & 54 & 65 \\
\hline 2006 & 38 & 21 & 55 & 62 \\
\hline 2005 & 24 & 10 & 42 & 56 \\
\hline 2004 & 46 & 12 & 26 & 55 \\
\hline 2003 & 47 & 10 & 21 & 40 \\
\hline 2002 & 37 & 5 & 14 & 25 \\
\hline Subtotal & $\mathbf{2 4 9}$ & $\mathbf{8 8}$ & $\mathbf{3 5}$ & $\mathbf{5 3}$ \\
\hline Before 2002 & & 11 & & \\
\hline TOTAL & & $\mathbf{9 9}$ & & \\
\hline
\end{tabular}

\section{Connecting with Your Alumni via Facebook}

It is one thing to have an Alumni Facebook Group; it is another to make the group valuable to your alumni. An alumnus who joins such a group is usually interested in what events are transpiring on campus; accordingly, by using the group's messaging feature, the department can periodically send out electronic newsletters containing the latest updates regarding the program. While Facebook only allows simple, text-based messages to be sent, additional content in the form of photos and videos can be posted on the group's site, and alumni can then be informed of the existence of this content by the message. A side effect of sending out messages is its potential to generate discussion or feedback. To date, our department has sent out two newsletters to our alumni group; both times we have received multiple reply messages or Wall postings in response. Through use of an electronic newsletter and the posting of photos and/or videos of department activities, one keeps the content fresh, providing alumni members a reason to revisit the group's Facebook page.

It should be noted that usefulness is a two-way street; by allowing an alumnus to post material, the department provides a vehicle for additional communication between alumni and the department. One of the benefits of this approach is that some of our alumni are now advertising job opportunities at their place of employment through Wall postings. Additionally, the group provides a convenient mechanism for faculty members to assist alumni in their networking efforts. In one particular case, an alumna (albeit not from the department) attended an event where she mentioned to the author of this paper her desire to seek employment in a locale a significant distance away from where she currently works and asked for any assistance that could 
be rendered. The author was able to search through the Alumni Facebook Group's membership list and found one alumnus who resided in the specified locale. As both of these alumni are listed as Facebook friends of the author, it was a simple task to connect these two alumni together by going to the alumna's Facebook page and recommending the alumnus as a friend along with an accompanying note explaining the reason for the friend request. If neither alumni was a Facebook friend it would not have been a problem; as access to the Alumni Facebook Group is open to all Facebook members, the author could have simply directed the alumna to visit the page containing the group's membership list, look for a specific individual, then send that alumnus a message.

Another reason for electronically connecting with alumni is to have the ability to better conduct assessment regarding ABET Criterion 2, Program Educational Objectives. Among the expectations regarding Criterion 2 are that programs are to have in place a process that periodically documents and demonstrates that the objectives are based on the needs of the program's various constituencies, plus an assessment and evaluation process that periodically documents and demonstrates the degree to which these objectives are attained ${ }^{9}$. One of the methodologies commonly employed is the use of alumni surveys; unfortunately, over the past several years the department has had mixed results concerning the response rate to physically mailed surveys, with rates sometimes floundering in the single digits. Normally, the surveys conducted by our department were sent to alumni that were three and 10 years removed from graduation. However, in early 2008 a new survey instrument was adopted in an attempt to measure the degree to which our graduates were achieving the program educational objectives. To obtain a larger sample size for the dual purposes of evaluating the survey instrument and for reporting the results of the survey in the Self-Study that was being written at the time, it was decided to also include graduates who were either three or four years out from college as well. In the cover letter accompanying the survey, the importance of completing the survey was stressed as this data was being collected for use in an impending ABET site visit; accordingly, a higher response rate than normal was achieved. The breakdown by cohort, as well as the overall response rate to the survey, in documented in Table 3. This data will hence serve as the benchmark against with Facebook-based requests will be compared. Please note that the disparity between the "Cohort Size" and "Surveys Sent" columns is due to not having valid contact information for a handful of graduates.

Table 3. Results from Mailed 2007-08 Alumni Survey

\begin{tabular}{|c|c|c|c|c|}
\hline $\begin{array}{c}\text { Graduation } \\
\text { Year }\end{array}$ & $\begin{array}{c}\text { Cohort } \\
\text { Size }\end{array}$ & $\begin{array}{c}\text { Surveys } \\
\text { Sent }\end{array}$ & $\begin{array}{c}\text { Surveys } \\
\text { Received }\end{array}$ & $\begin{array}{c}\text { Response } \\
\text { Rate, \% }\end{array}$ \\
\hline 2004 & 46 & 41 & 16 & 39 \\
\hline 2003 & 47 & 47 & 8 & 17 \\
\hline 2002 & 37 & 36 & 9 & 24 \\
\hline 1997 & 29 & 29 & 7 & 24 \\
\hline TOTAL & $\mathbf{1 5 9}$ & $\mathbf{1 5 4}$ & $\mathbf{4 0}$ & $\mathbf{2 6}$ \\
\hline
\end{tabular}




\section{Requesting Information through Facebook Groups}

To determine the effectiveness of using Facebook Groups for requesting information from our graduates, two exercises were conducted in the fall of 2008. One of the questions that is often asked by prospective students or their parents is with regard to what sort of job one can get with a degree in a particular field. To assist in answering this question, the first exercise involved requesting members of our Alumni Facebook Group to mail in one of their business cards. The group members were all sent a message that first stated the often-asked question, then requested that they contribute to a planned display of business cards that would creatively serve as a visual aid for addressing this question. In order to comply with this request, an alumnus would have to go through the trouble of addressing an envelope, inserting the card, and placing it in the mail, which is similar to the effort needed for responding to a mailed survey. In the first two weeks, only 10 business cards were received; fortunately, because Facebook is an electronic medium, it was simple to send out another message at that time thanking those who had already sent in their cards while encouraging others that there was still time to send their cards in. An additional 15 business cards were then received.

Three months after the first exercise, an electronic newsletter was sent out as a message to all members of the ECCS Alumni Facebook Group. As part of that newsletter, a request was made for assistance with the evaluation of changes made to the senior design course sequence. The alumni were asked to take a few minutes to fill out a short survey regarding their senior design experiences, regardless of the year of graduation, which was hosted at SurveyMonkey.com; a link to the survey was provided with the request. While it should come as no surprise that electronic communications are faster than the use of surface mail, it is interesting to note that five responses to the survey were started within 10 minutes of the message being sent, and 16 responses were received by midnight. The response rate subsequently slowed down, with six responses on the second day, then at least one response received on each of the next four days; however, some responses continued to trickle in, with the last response received one month following the newsletter request. Unlike the business card request, no secondary reminder was sent out to the group. Table 4 presents the results of the two exercises, broken down by cohort.

Table 4. Ohio Northern ECCS Alumni Facebook Group Responses (as of 16 January 2009)

\begin{tabular}{|c|c|c|c|}
\hline $\begin{array}{c}\text { Graduation } \\
\text { Year }\end{array}$ & $\begin{array}{c}\text { Members of } \\
\text { Alumni Group }\end{array}$ & $\begin{array}{c}\text { Business } \\
\text { Card Sent }\end{array}$ & $\begin{array}{c}\text { Survey } \\
\text { Response }\end{array}$ \\
\hline 2008 & 17 & $4(24 \%)$ & $7(41 \%)$ \\
\hline 2007 & 13 & $2(15 \%)$ & $2(15 \%)$ \\
\hline 2006 & 21 & $5(24 \%)$ & $7(33 \%)$ \\
\hline 2005 & 10 & $2(20 \%)$ & $4(40 \%)$ \\
\hline 2004 & 12 & $3(25 \%)$ & $4(33 \%)$ \\
\hline 2003 & 10 & $1(10 \%)$ & $3(30 \%)$ \\
\hline 2002 & 5 & $2(40 \%)$ & $0(0 \%)$ \\
\hline Subtotal & $\mathbf{8 8}$ & $\mathbf{1 9 ( 2 2 \% )}$ & $\mathbf{2 7 ( 3 1 \% )}$ \\
\hline Before 2002 & 11 & $6(54 \%)$ & $7(64 \%)$ \\
\hline TOTAL & $\mathbf{9 9}$ & $\mathbf{2 5 ( 2 5 \% )}$ & $\mathbf{3 4 ( 3 4 \% )}$ \\
\hline
\end{tabular}


When comparing the response rates to the "very important as it's needed for ABET" mailed survey, both exercises turned out well. Requests for business cards do not carry much, if any, urgency, yet the response rate of $25 \%$ was similar to that of the aforementioned heavily solicited mailed survey and was higher than the response rates for prior mailed surveys. The overall response rate for the electronic survey, even though that request was hidden inside a newsletter instead of explicitly asked, was significantly higher at $34 \%$, relative to the rate for the business card request. This increase can be attributed to the ease of which one could respond to the request: simply click on the provided link and be taken to the survey site.

\section{Conclusions and Future Plans}

This paper has presented a methodology that can be readily adapted by any department that wants a faster, most cost-effective way of maintaining connections with their alumni and, in so doing, help themselves to better collect assessment data in support of ABET Criterion 2. Advantages of using a social network service such as Facebook can be found both in the communication features provided for use and in its inherent interactive nature. Additionally, social network services provide not only a way for the department to communicate with alumni, but also a way for alumni to communicate with each other; this has already resulted in employment opportunities being advertised by alumni for alumni, which tremendously adds value to the site. Two exercises were conducted that provided increased response rates to requests for information when compared to traditional paper surveys. Furthermore, the response rate was shown to increase significantly when an electronic response method was utilized.

One area under consideration for future development is examining ways to increase the group membership rate of students belonging to a social network service. The data in Table 1 indicates that the percent of cohort members having a Facebook account rose dramatically since Facebook's inception, but has now leveled off to percent values in the mid-80s. Similarly, the participation rate of cohort members being part of the Alumni Facebook Group is hovering in the $50-55 \%$ range. While obtaining a $100 \%$ participation rate appears to be overly idealistic, achieving a rate above $80 \%$ seems reasonable. To that end, the members of the 2009 graduating cohort will receive materials prior to graduation inviting them to join the Ohio Northern ECCS Alumni Facebook Group, including information regarding Facebook if they are not a member of that social network service. This invitation will be followed up during the Senior Exit Interview to obtain feedback from those who do not (at least initially) join to determine what, if anything, the department can do to further encourage the use of the ECCS Alumni Facebook Group.

To conclude on a personal note, developing the Ohio Northern ECCS Alumni Facebook Group has allowed the author to become better connected with the department's alumni. Through their messages, alumni have indicated their appreciation of the news provided of the department, of the initiatives promoted through the group, and of the opportunities that have been offered for making connections. Knowing of this appreciation has made this effort a rewarding experience. 


\section{Bibliography}

1. D. M. Boyd and N. B. Ellison, "Social network sites: Definition, history, and scholarship." Journal of Computer-Mediated Communication, 13(1), article 11, 2007. Online: http://jcmc.indiana.edu/vol13/issue1/boyd.ellison.html

2. M. Hauben and R. Hauben, "Netizens: On the History and Impact of Usenet and the Internet." IEEE Computer Society Press, 1997.

3. J. C. R. Licklider and R. W. Taylor, "The Computer as a Communication Device." Science and Technology, 1968; reprinted in "In Memoriam: J. C. R. Licklider 1915-1990", Research Report 61, Digital Equipment Corporation Systems Research Center, August 1990. Online: http://gatekeeper.dec.com/pub/DEC/SRC/publications/taylor/licklider-taylor.pdf

4. J. Whyte, "Social Network Advertising, Part 1." Online: http://www.searchmarketingstandard.com/blog/2007/07/social-network-advertising-part-1.html

5. Facebook Fact Sheet. Online: http://www.facebook.com/home.php?ref=home\#/press/info.php?factsheet

6. Facebook group, "If I want to Complain, $\$ 40,000$ says you should listen." Online: http://www.facebook.com/group.php?gid=46586957365

7. Facebook group, “America's Roller Coast: Fans of Cedar Point, Sandusky, Ohio.” Online: http://www.facebook.com/group.php?gid=2204697727

8. S. Shapiro, "Revolution, Facebook-Style." New York Times Magazine 25 Jan. 2009, Online: http://www.nytimes.com/2009/01/25/magazine/25bloggers-t.html

9. ABET, "2009-2010 Criteria for Accrediting Engineering Programs." Online: http://abet.org/Linked\%20Documents-UPDATE/Criteria\%20and\%20PP/E001\%200910\%20EAC\%20Criteria\%2012-01-08.pdf 